\title{
Local Area Distribution of Fallout Radionuclides from Fukushima Daiichi Nuclear Power Plant Determined by Autoradiography Analysis
}

\author{
Fuminori SAKAMOTO ${ }^{1}$, Toshihiko OHNUKI ${ }^{1, *}$, Naofumi KOZAI ${ }^{1}$, \\ Shosuke IGARASHI ${ }^{1,2}$, Shinya YAMASAKI ${ }^{1}$, Zenko YOSHIDA $^{1}$ \\ and Shunichi TANAKA ${ }^{3}$ \\ ${ }^{1}$ Japan Atomic Energy Agency, 2-4 Shirane, Shirakata, Tokai-mura, Naka-gun, Ibaraki 319-1195, Japan \\ ${ }^{2}$ Ibaraki University, 2-1-1 Bunkyo Mito-shi, Ibaraki 310-8512, Japan \\ ${ }^{3}$ NPO Radiation Safety Forum, 27F Shiroyama-Trust Tower, Toranomon, Minato-ku, Tokyo 105-6027, Japan
}

\begin{abstract}
The environmental behavior of radioactive Cs in the fallout from the accident of the Fukushima Daiichi Nuclear Power Plant has been studied by measuring its spatial distribution on/ in trees, plants, and surface soil beneath the plants using autoradiography analysis. The results of autoradiography analysis showed that radioactive Cs was distributed on the branches and leaves of the grown trees and that only a small fraction of radioactive Cs was transported to new branches and leaves merged after the accident. Radioactive Cs was present on the grass and rice stubble on the soils, but not in the soils beneath the grass and rice stubble, indicating that the radioactive Cs was deposited on the grass and the rice plant. In addition, a small fraction of the deposited radioactive Cs was released by weathering for two months after the accident. These results indicate that trees and other plants are the reservoir of the fallout Cs and function to retard the fallout Cs migration with rain water.
\end{abstract}

KEYWORDS: radioactive fallout, radioactive Cs, accumulation in plant, migration, autoradiography

\section{Introduction}

A large amount of various nuclear fission products (hereinafter referred to as "radioactive material") was released into the environment by the core meltdown and hydrogen explosion at the Tokyo Electric Power Fukushima Daiichi Nuclear Power Plant on March 11th, 2011. Judging from the observation that the radioactive materials released by the hydrogen explosion at Unit-2 on the morning of March 15th were transported to the northwest by southeast winds, followed by precipitation/snow from the evening into the night on that day, the radioactive materials probably fell on Namie-machi, Fukushima-Prefecture, Iitate-mura and Kawamata-machi of the same prefecture, and elsewhere ${ }^{1,2}$. The major portion of the radionuclides that fell in the area were ${ }^{131} \mathrm{I},{ }^{134} \mathrm{Cs}$, and ${ }^{137} \mathrm{Cs}$. Because of a short half-life of approximately 8 days for ${ }^{131} \mathrm{I}$,

\footnotetext{
* Corresponding author, E-mail: ohnuki.toshihiko@jaea.go.jp

DOI : 10.15669 /fukushimainsights. Vol.4.52

(C) 2021 Atomic Energy Society of Japan. All rights reserved.

Originally published in Transactions of the Atomic Energy Society of Japan (ISSN 1347-2879), Vol. 11, No. 1, p.1-7 (2012)

in Japanese. (Japanese version accepted: September 6, 2011)
} 
the radionuclides detected after May were mainly ${ }^{134} \mathrm{Cs}$ (half-life of approx. 2.1 years) and ${ }^{137} \mathrm{Cs}$ (half-life of approx. 30 years) ${ }^{3)}$.

The vertical distribution of the radioactive fallout was measured by Naganawa et al. using a $\mathrm{NaI}$ scintillation counter in such a manner that the soils were sampled at a spacing of approximately $10 \mathrm{~mm}$ for dry land soils, pastures, and paddy fields. It was clarified that nearly all of the radioactive fallout was distributed within the top $100 \mathrm{~mm}$ of the land surface ${ }^{4}$. However, it is believed that the radioactive fallout accumulated not only in soil but also in trees and chamaephytes, but its distribution and accumulation on soils, trees, chamaephytes, etc. has not yet been clarified.

To measure the distribution of radioactive materials, sampling the soil layer to a defined depth is effective, as previously explained. In such measurement, intervals in the vertical direction of the soil sample determine resolution in the depth direction. For this reason, $10 \mathrm{~mm}$ deep is considered the limit for an environmental specimen. Similarly, because reducing the cutting to obtain a higher resolution for the trees may result in measurement count decrease, $10 \mathrm{~mm}$ was considered the limit.

Using autoradiography, the distribution of radioactive materials is measured by leaving a specimen directly on an imaging plate sensitive to the radiation, for a certain period of time ${ }^{5}$. One disadvantage is that the individual identification of radioactive materials is not possible because all radiation is detected. Among the radioactive materials deposited in Fukushima-Prefecture, the radionuclides detected during May and after, as previously explained, were ${ }^{134} \mathrm{Cs}$ and ${ }^{137} \mathrm{Cs}$. Because of this, it was possible to measure the distribution of the radioactive fallout in a local area smaller than $10 \mathrm{~mm}$ using autoradiography, and to investigate its short-term mobility after the initial fallout.

In this report, the distribution of radionuclides was measured using autoradiography on trees, chamaephytes, and soils sampled on May 14th in Iitate-mura, Kitasoma-gun, and Fukushima-Prefecture, to study the local area distribution of fallout. Furthermore, as well as studying the distribution of radioactive Cs after deposition, decontamination was analyzed and discussed.

\section{Methodology}

\section{Specimen Sampling}

The sampled trees were Cryptomeria japonica, Torreya nucifera, and Prunus mume growing near the site of the decontamination experiment. Branches with leaves were sampled for Cryptomeria japonica and Torreya nucifera and used as specimens. Regarding the Torreya nucifera branches, those leaves with less green on the branch tips were considered to have grown following the spring and were selected. Regarding the Cryptomeria japonica, stems with a diameter of approximately $50 \mathrm{~mm}$ were sampled and used as specimens for measuring the distribution of radioactive materials in trees. The stems selected were those grown in a nearly horizontal direction. As for chamaephytes, Petasites japonicus and fern relatives were sampled. There were no plants such as trees that covered the Petasites japonicas. On the other hand, fern relatives were sampled in the grove. There were trees above the fern relatives, so it was assumed that direct accumulation of rainfall/snowfall did not occur.

Regarding the soil specimens, a location where pastures and Oryza sativa stubble remained was chosen and the soil layer was sampled to a depth of approximately $50 \mathrm{~mm}$, with care to avoid disturbing the soil layers. For information, stubbles was sampled with the roots and soil 
immediately under the stubble.

\section{Specimen Preparation}

No special preparation was conducted for sampling the branches and leaves of trees and chamaephytes to measure the distribution of radioactive materials using autoradiography. To measure radionuclide distribution in a Cryptomeria japonica stem section, a stem portion approximately $50 \mathrm{~mm}$ in diameter was cut into approximately 5 -mm-thick slices. This preparation was conducted at the stem sampling site. For soil sample preparation, vertical cuts were made in the pasture in the stubble zone, down into the soil, and the section was fixed by gluing and cutting to an approximately $5 \mathrm{~mm}$ thickness for autoradiograph measurement. The number of specimens used for measurement was one because the sampling was conducted in a planned evacuation area.

\section{Autoradiography Measurement}

The tool used for autoradiography measurement was a bio imaging analyzer BAS2500 (Fujifilm, Japan, BAS2500). The spatial resolution of the imaging plate was $0.05 \mathrm{~mm}$. After exposing the prepared samples on the imaging plate for 24 or $48 \mathrm{~h}$, the area exposed to radiation was developed using a reading and analysis unit of the imaging plate. In the resulting image, the higher the intensity of the radiation, which is directly related to the concentration of radionuclides, the darker the blackness of the image. Furthermore, it is possible to separately analyze two levels of intensity in a single image by varying the intensity gradient of the radiation. During measurement, the specimen was covered with a thin film of polyvinylidene chloride to prevent contamination of the imaging plate by the specimen. After measurement, an optical photo of the specimen was taken with the polyvinylidene chloride film in place. Before the autoradiography measurement, the intensity of the radiation from the specimen was measured with a NaI scintillation counter (Aloka, TCS161). Also, the contained radionuclides on some of the specimens were measured using a $\gamma$-ray spectrum analysis system. For the Torreya nucifera branches and leaves, the concentration of radionuclides was measured using a $\gamma$-ray spectrum analysis (Ge semiconductor detector) system after individually cutting off two portions showing the difference in blackness (see the Results and Discussion) after the completion of the autoradiography measurement.

\section{Results and Discussion}

\section{Distribution on Trees}

Cryptomeria japonica branches showed a slight blackening on the branches and leaves in the autoradiography analyses (Figure 1). Approximately 2-mm-wide black spots were observed on the branches. As shown in the optical photograph (Figure 2) of the sliced Cryptomeria japonica stems, distinct black spots are observed on the stem surface. The spots are not distributed all over the stem, but on the epidermis in the upper part of the stems. The images of the two sides are nearly symmetrical at the portion with an arrow in the autoradiograph image, while in the portion surrounded by a rectangle the spots were detected only on one of the surfaces. This was caused by the epidermis loss that occurred during the replacement of the specimen. Inside the 


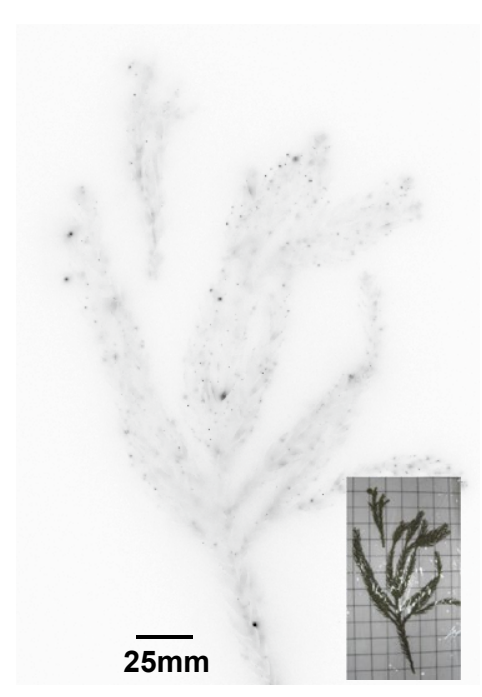

Figure 1 Autoradiograph image and optical photograph (inset) of branch and leaves of Cryptomeria japonica
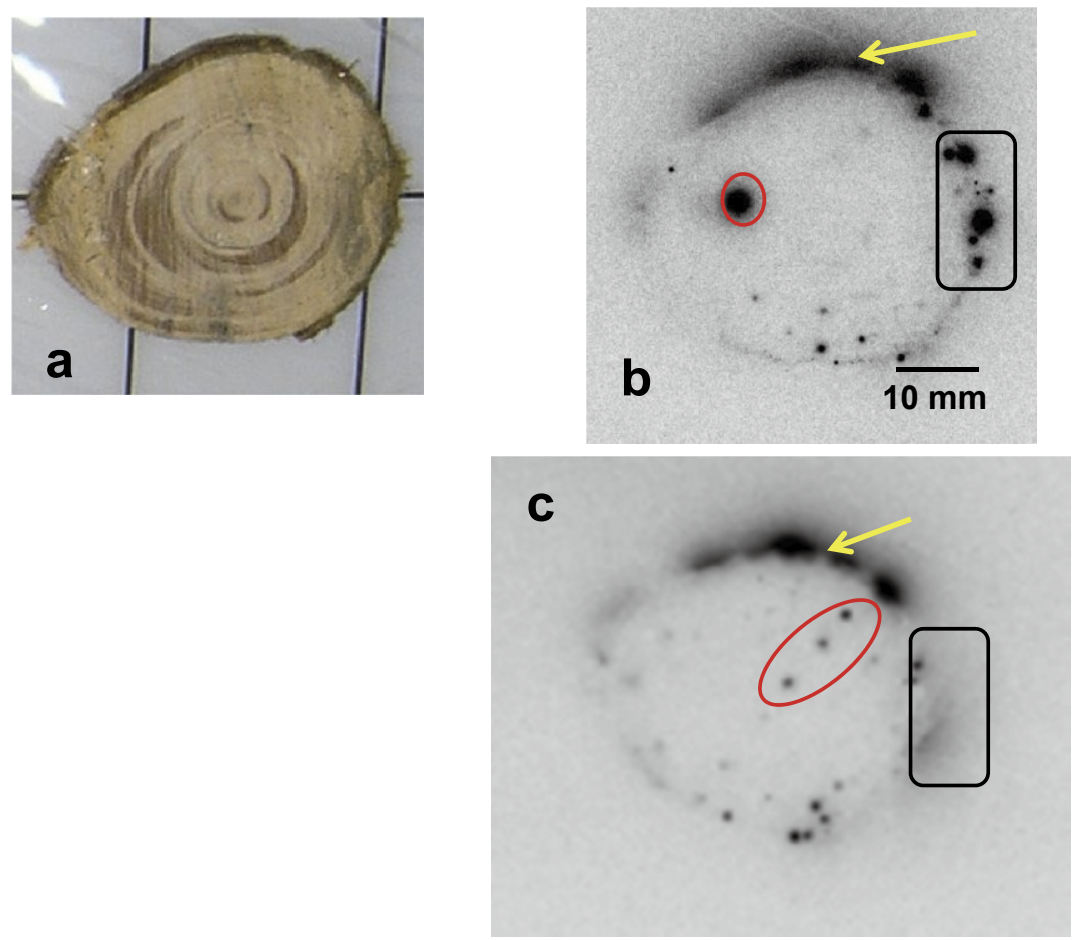

Figure 2 Cross sections of stem of Cryptomeria japonica

Optical photograph (a), autoradiograph images of both sides of the cross section (b), and (c). Note that image (c) is the result of a horizontal flip of the sample. 
stem, black spots were detected, but the spot positions differed between the two sides of the stem section. This indicated that the spots on the stem were not caused by radioactive materials that penetrated into the stem, but by contamination after the cutting of the stem. Additionally, because ${ }^{40} \mathrm{~K}$ is contained in the plants, there is a concern that the spots detected by autoradiography might have been caused by ${ }^{40} \mathrm{~K}$. The radioactivity measured on the stems, branches, and leaves using a scintillation counter showed several times higher intensity than that of the background radiation.

Based on the above discussion, most of the spots detected by autoradiography are considered the product of radioactive Cs. Thus, as the specimens' radioactivity as measured by the scintillation counter was more than twice that of the background, the influence of ${ }^{40} \mathrm{~K}$ will not be considered further.

Analysis of branches and leaves of Torreya nucifera using autoradiography (Figure 3) detected radioactive materials all over the branches, with numerous black spots on both branches and leaves. Furthermore, when the leaves of Torreya nucifera were separated according to their elevation on the tree, a series of scintillation counter measurements on the leaves showed 1.8 times higher radiation intensity than those collected at higher position. The trend of a higher intensity in the upper part was the same for three branches in different locations, confirming the greater accumulation of radioactive fallout on the higher leaves.

However, the blackness of the branch tips (surrounded by a red oval) is less intense than in other areas of the branch. So a $\gamma$-ray spectrum analysis was conducted on the low blackness (red oval 1) and high blackness (blue oval 2) regions. As a result, clear peaks of ${ }^{134} \mathrm{Cs}$ and ${ }^{137} \mathrm{Cs}$ were confirmed in the $\gamma$ spectrum in the red and blue areas and the Cs- 137 counts were 660 counts $/ g$ dry and 1,790 counts/g dry, respectively. Because the greenness of the leaves in the tip area of the branches was thinner than other areas in the optical photograph shown in Figure 3, the tip area is considered to be branches and leaves that grew after this spring. These results show lower radioactivity in the branches and the leaves that emerged this year than in those that grew in the previous year. Thus, it was concluded that the radioactive fallout did not deposit directly on the new branches and leaves, but was concentrated after deposition.

The autoradiography analysis of the Prunus mume branch and its sliced fruit (Figure 4) showed a clear black zone in the branch. On the other hand, the blackness of the fruits and

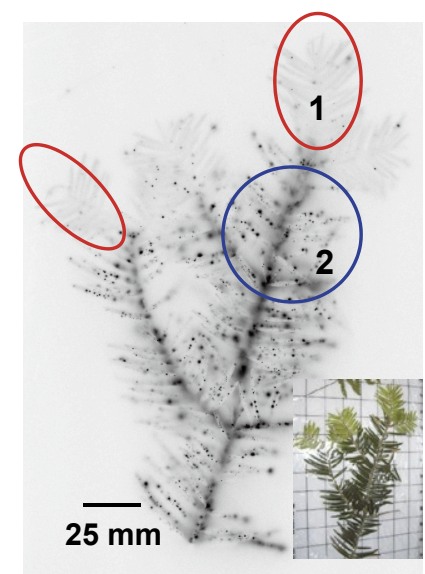

Figure 3 Autoradiograph image and optical photograph (inset) of branch and leaves of Torreya nucifera 

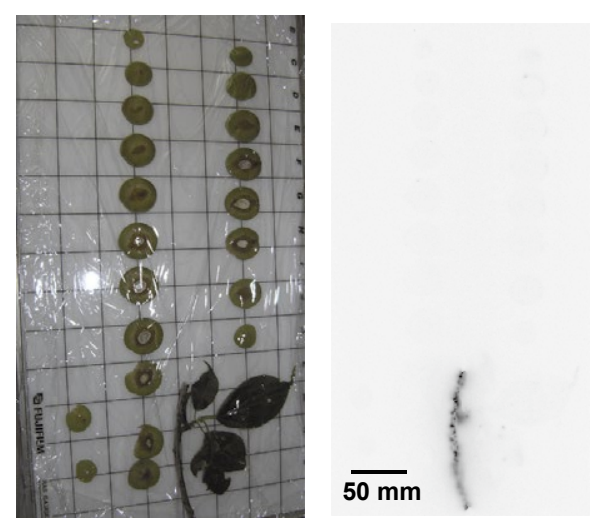

Figure 4 Autoradiograph image (right) and optical photograph (left) of branch and leaves, and cross sections of fruits of Prunus mume

leaves was extremely low compared to the branch area.

All the aforementioned results suggest that the radioactive materials concentrated in the trees were concentrated on the portion that had already grown during the previous year, i.e. before the accident at the Fukushima Nuclear Power Plant. Because the radioactive material concentration in the stem of the branches was extremely low, it is considered that the portion transported to the leaves from the roots through the stem was very low. Accordingly, direct adhesion of radioactive fallout to aged and therefore rougher-surfaced growth is a probable process. Furthermore, only some portion of the radioactive material was found in the new branches and leaves. Tsukada et al. conducted an experiment to affix ${ }^{137} \mathrm{Cs}$ to radish leaves and reported that part of the ${ }^{137} \mathrm{Cs}$ was absorbed from the leaf surface ${ }^{6}$. Our results indicate absorption and translocation from the leaves of the needle leaf tree, Torreya nucifera, as well.

\section{Distribution to Chamaephytes}

The autoradiography analysis of surface soil containing meadow grass sampled in pasture land is shown in Figure 5 together with optical photographs. A yellow dotted line in the optical photograph indicates the land surface. The meadow grass is present in the upper part of the land surface and roots are seen in the lower part. In the autoradiography image, a uniformly high blackness is seen in the upper part of the ground with some black spots and no black area lower than the land surface. The result indicates that nearly no penetration of radioactive fallout occurred below the land surface, but remained in the meadow grass. Naganawa et al. showed the possibility of distribution of most of the radioactive materials within $30 \mathrm{~mm}$ of the surface of pasture land ${ }^{4}$. Our results indicate that there was no penetration of radioactive materials into the soil immediately under the pasture where plants such as meadow grasses are growing.

The image acquired by autoradiography of a stubble section of Oryza sativa in the paddy fields (Figure 6) shows the black portion in the stubble. The blackness of the soil portion has the same level as that of the background indicating that the concentration of radioactive material is below the detection limit of autoradiography, showing that the radioactive fallout on stubble was concentrated in the stubble portion.

Analyses of Petasites japonicus are shown in Figure 7 together with an optical photograph. The area in the oval in the optical photograph indicates the root of Petasites japonicus. Black areas are uniformly seen in the stem and leaf area. In the stem, the shape of the black area nearly 


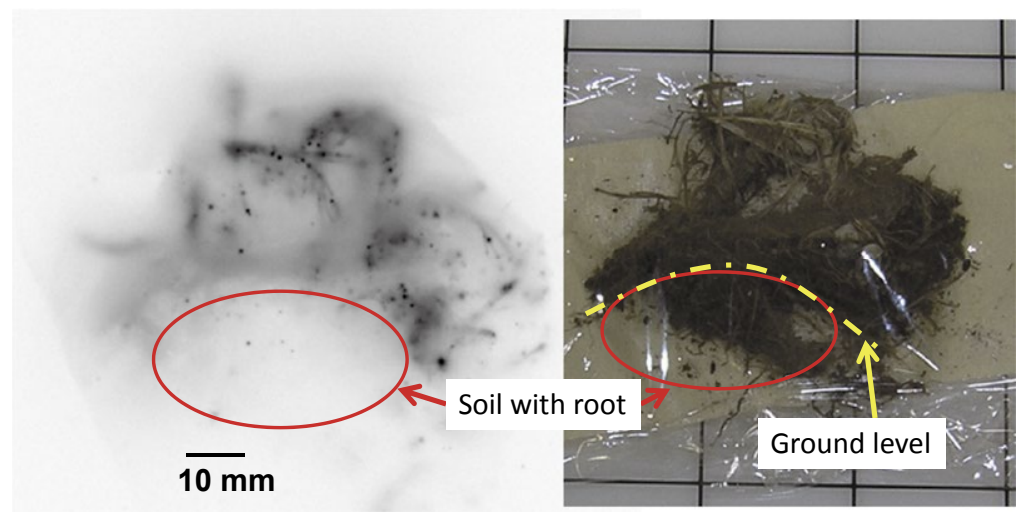

Figure 5 Autoradiograph image (left) and optical photograph (right) of cross section of meadow grass with soil beneath the grass

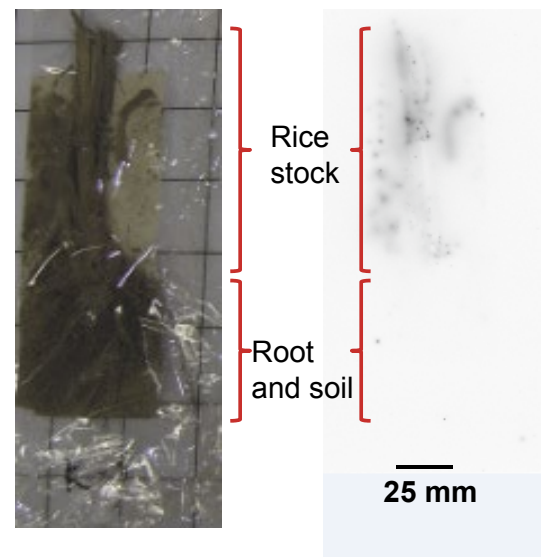

Figure 6 Autoradiograph image (right) and optical photograph (left) of stubble of Oryza sativa with paddy soil beneath the stubble

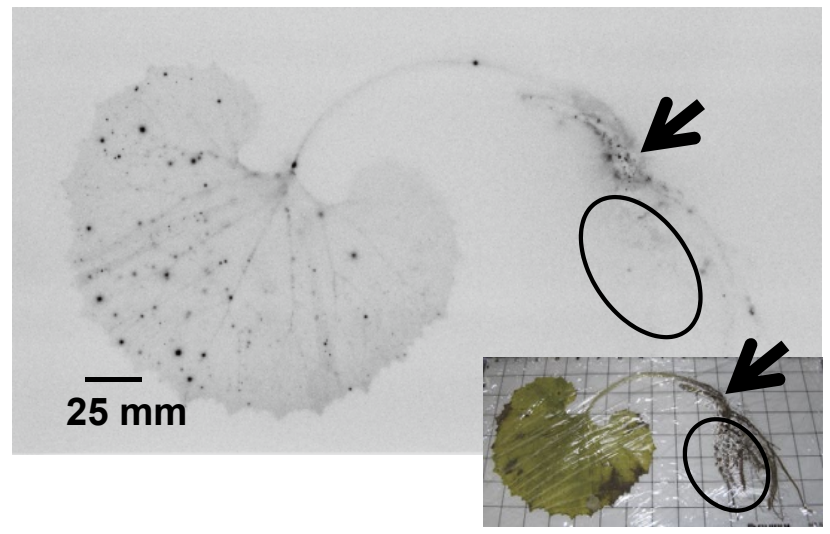

Figure 7 Autoradiograph image and optical photograph (lower right) of Petasites japonicus with soil 


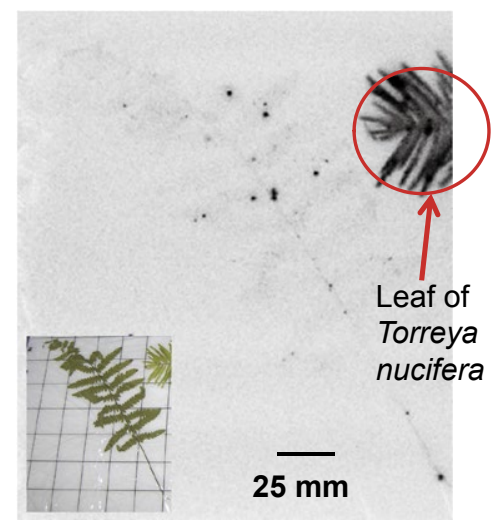

Figure 8 Autoradiograph image and optical photograph (inset) of fern relatives

coincides with that of the stem in the optical photograph. On the other hand, the blackness in the root is approximately the same as that of the background. The black spots, considered to indicate concentrations of radioactive materials, are seen in the leaf area of Petasites japonicus. This concentration is a result of the absorption/accumulation via the roots or secondary transmission of radioactive materials adhering to soil particles. Furthermore, radioactive materials are observed in the area of the ground surface (indicated with an arrow) and the blackness is darker than that of the stem and leaf areas. There was no tree (such as Cryptomeria japonica) over the sampling point of Petasites japonicus. It was assumed that Petasites japonicus had not grown when the deposition of radioactive fallout occurred. Because accumulation of radioactive materials is seen in the stem area, absorption from the roots is implied.

The autoradiography analysis of fern relatives sampled in the grove (Figure 8) shows that there was nearly no accumulation of radioactive materials. The radioactivity of the fern relatives measured with a scintillation counter was nearly the same as background, indicating that there was nearly no accumulation of radioactive Cs on the fern relatives. The upper parts of the sampled fern relatives were covered by trees such as Cryptomeria japonica. These results implied that most of the radioactive materials were intercepted by the trees above the fern relatives and did not fall on them.

\section{Local Area Translocation of Radioactive Materials from the Fukushima Nuclear Power Plant after Initial Deposition}

The radioactive materials released into the atmosphere from the Fukushima Nuclear Power Plant fell in Iitate-mura on March 15th. Based on the AMEDAS data of that day ${ }^{7}$, precipitation was $0.5-1.5 \mathrm{~mm} /$ hour after $17: 00$. Furthermore, the temperature was $2^{\circ} \mathrm{C}$ or lower, below $1^{\circ} \mathrm{C}$ after 20:00, and below $0^{\circ} \mathrm{C}$ after 24:00. Given these data, there was a high possibility of snow instead of rain, or freezing immediately after rainfall.

In the case of rainfall, water droplets that fall on the ground will flow along the gradient of the land surface or penetrate the soil vertically. Accordingly, the distribution of radioactive materials contained in the rain is considered not to be much influenced by the location of trees, chamaephytes, etc., but fairly uniform. However, in the case of rainfall/snow (hereinafter in this paper "rainfall/snow" refers to both snowfall and freezing after rainfall), stagnation occurs on the upper branches and leaves of trees. Furthermore, rainfall/snow will stagnate on the chamaephytes in pastures and soils and will have less of a chance to flow over the land surface 
than simple rainfall, whatever the gradient of the land. For this reason, any radioactive material contained in rainfall/snow remains on the precipitated location longer than rainfall during the early stage of deposition.

In our study, it was recognized that accumulation of fallout was seen in the upper part of the stem surface of the sliced Cryptomeria japonica, more accumulation on the leaves that were present in the upper part of Torreya nucifera leaves, and nearly none in the fern relatives that were sampled in the grove. This resulted from the non-uniform distribution of fallout under rainfall/snow conditions. Furthermore, the concentration of radioactive fallout in the upper part of the land surface, particularly on pastures, in the soils, and on rice stubble, can be explained as a peculiar behavior of radioactive materials in rainfall/snow.

The behavior of radioactive materials accumulating in snow piled up on trees and pastures post-melting has scarcely been studied until now. No rainfall was observed around Iitate-mura on March 16th, and the temperature was generally below $2^{\circ} \mathrm{C}$. This implies a slow melting rate for snow, i.e. a longer duration of the contact between the radioactive fallout contained in the snow or ice and the trees, pastures, and soils than during simple rainfall.

The radioactive Cs deposited on the surface of the chamaephytes is considered to have been transported to the inner plant and soil layers through leaf surface absorption or weathering, respectively ${ }^{8}$. According to Kawabata et al., more than $80 \%$ of the Cs deposited as solid aerosol on Raphanus sativus var. sativus was removed from the outer plant by weathering resulting from rainfall ${ }^{9)}$. The radioactive Cs transported to the soil was tightly adsorbed by a so-called 2:1 type clay mineral similar to mica ${ }^{10-12)}$. Based on this, during the translocation of radioactive Cs deposited on the plants via soil, a delaying role of the soil is expected. Our results imply that, in the actual conditions for 2 months after the fallout, the effect of weathering was very low because of the immobility of the radioactive Cs accumulated on the chamaephytes and trees. Accordingly, the pastures contributed greatly to a delay in translocation of the fallout as it penetrated the soil via rainfall water from plants and soil surfaces.

\section{Decontamination of Plants and Pasture Lands}

In regions in Fukushima-Prefecture, where the radioactive Cs concentration is high, radioactive Cs was detected on the stem epidermis, branches and leaves of trees. Detergent was considered as a decontamination tool ${ }^{6}$ to wash away Cs that had adhered to trees, etc. So, autoradiography measurement was conducted after dipping Torreya nucifera branches and leaves in a detergent solution. However, there was nearly no change after dipping in the detergent solution, perhaps because of strong binding of radioactive Cs to surfaces, or even actual accumulation into the trees. This suggested that trimming the trees might be more effective. Additionally, our results indicated higher contamination in the upper regions of the trees, which suggested reducing the dose of the whole tree by trimming just the upper part. Furthermore, because of the limited penetration of radioactive Cs in the stem, the possibility of preventing penetration from the surface to the inside by promptly trimming the branches and leaves with a high dose is recommended. Consequently, given the precondition of confirmed radioactivity, it is strongly indicated that trees such as Cryptomeria japonica be used as architectural material after removing their epidermis.

Nearly no penetration of radioactive Cs into the soil was observed in the decontamination of pasture lands. This implies the possibility of effective decontamination of pasture lands by collecting just their surface portion. However, because the rainfall total increases with time after the fallout, the possibility of re-translocation of concentrated radioactive Cs on the pastures cannot be denied. As well as the necessity of promoting studies on the chemical status of 
concentrated radioactive Cs, it would be effective to decontaminate the pasture by promptly collecting surface soils/plants.

These results are important knowledge for future decontamination operations. However, because our results are only from a single region, further data collection will be necessary for the decontamination of a wider range of area types. When conducting a survey of the distribution of radionuclides, visualized data from autoradiography as well as the concentration distribution will contribute to the preparation of a detailed decontamination plan and its understanding by residents.

\section{Summary}

The local area distribution of radioactive materials was measured using autoradiography, targeting trees, chamaephytes, and soils. The behavior of the radioactive Cs component of the fallout after precipitation was studied. As a result, the following conclusions can be made:

- The radioactive Cs that was deposited on the trees accumulated more on the stems and leaves that were present before the fallout. Furthermore, some of the radioactive Cs was distributed on the new branches and leaves that grew after the fallout.

- Most of the radioactive Cs that was deposited on pastures and rice stubble accumulated on the vegetation, and secondary movement to the soils immediately beneath was below the detection limit of this method.

- Rainfall/snow is considered to be one of the reasons for the non-uniform concentration of radioactive Cs on the plants.

Consequently, chamaephytes and trees have acted as accumulation media, greatly inhibiting the further translocation of radioactive Cs, either in the soil or in runoff.

\section{References}

1) M. Chino, H. Nakayama, H. Nagai et al., "Preliminary estimation of release amounts of ${ }^{131} \mathrm{I}$ and ${ }^{137} \mathrm{Cs}$ accidentally discharged from the Fukushima Daiichi Nuclear Power Plant into the atmosphere," J. Nucl. Sci. Technol., 48, 1129-1134 (2011).

2) A. Omoto, ICAPP2011 Special Japan Session: Presentation Nice, France, May 2-6, 2011. file is available athttp://www.aesj.or.jp/information/fnpp201103/icapp2011_Omoto_WEBrevision20110517.pdf

3) MEXT, Measurements on Dust Sampling, Environmental Specimens and Soil Monitoring around Tokyo Electric Fukushima Daiichi and Daini Nuclear Power Plants: Measurements of Soil Monitoring (as of 10:00, Jun.25, 2011) http://www.mext.go.jp

4) H. Naganawa, N. Kumazawa, H. Saitoh et al., "Removal of Radioactive Cesium from Surface Soils Solidified Using Polyion Complex - Rapid Communication on Decontamination Test at Iitate-mura in Fukushima Prefecture," Transactions of the Atomic Energy Society of Japan. (To be published).

5) F. Sakamoto, T. Ohnuki, T. Fujii, et al., "Response of Saccharomyces cerevisiae to heavy element stress: lead vs. uranium," Geomicrobiol. J. (To be published).

6) H. Tsukada, H. Hasegawa, H. Kawabata et al., "Leaf Surface Absorption of ${ }^{137} \mathrm{Cs}$ by Droplet Impregnation," 2009 Fall Meeting of Atomic Energy Society of Japan, Abstract A23 (2009).

7) JMA, AMEDAS Hp (http://www.jma.go.jp/jp/amedas/)

8) H. Amano, T. Takahashi, S. Uchida, et al., "Development of a code MOGRA for predicting the migration of ground additions and its application to various land utilization areas," J. Nucl. Sci. Technol., 40, 975-979 (2003).

9) H. Kawabata, H. Hasegawa, H. Tsukada et al. "Behavior on Leaf Surface of Crop Plants," Annual Report FY2009/Institute for Environmental Sciences/Institute for Environmental Science, 20-24 (2010).

10) T. Ohnuki, "Sorption characteristics of cesium on sandy soils and their components," Radiochimica Acta, 65, 75-80 (1994).

11) T. Ohnuki, N. Kozai, "Sorption characteristics of radioactive cesium and strontium on smectite," 
Radiochim. Acta, 66/67, 327-331 (1994).

12) D. J. Assinder, S. M. Mudge, G. S. Bourne, "Migration of ${ }^{137} \mathrm{Cs}$ and ${ }^{90} \mathrm{Sr}$ from Chernobyl fallout in Ukrainian, Belarussian and Russian soils," J. Environmental Radioactivity, 35, 1-19 (1997). 